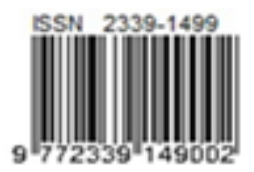

\title{
Pengukuran Kinerja Rantai Pasok Dengan Model Supply Chain Operations Reference (SCOR) dan Metode Perbandingan Berpasangan
}

\author{
David Try Liputra ${ }^{1}$, Santoso $^{2}$, Nadya Ariella Susanto ${ }^{3}$ \\ 1,2,3) Fakultas Teknik, Program Studi Teknik Industri, Universitas Kristen Maranatha \\ Jl. Prof. drg. Surya Sumantri, M.P.H. No. 65, Bandung 40164 \\ Email: david.t|@eng.maranatha.edu1, santoso@eng.maranatha.edu²
}

\begin{abstract}
The rapid development of the industrial world has resulted in increasingly tight competition among companies. This condition shows the importance of improving performance, not only in a company but also other parties in the related supply chain, in order to compete with other companies or supply chains. The good performance of a supply chain will certainly increase the customers satisfaction. Therefore, performance measurement needs to be carried out so that a supply chain can find out how well it currently performing is and keep improving it. This study will discuss about the application of the supply chain operations reference (SCOR) model and the pairwise comparison method for the supply chain performance measurement of a product packaging company.
\end{abstract}

Keywords: supply chain, performance measurement, SCOR, pairwise comparison

\begin{abstract}
Abstrak
Perkembangan dunia perindustrian yang semakin pesat mengakibatkan persaingan yang terjadi antar perusahaan juga semakin ketat. Kondisi ini menunjukkan pentingnya peningkatan kinerja, tidak hanya dalam suatu perusahaan tetapi juga pihak-pihak lain pada rantai pasok yang terkait, agar dapat bersaing dengan perusahaan atau rantai pasok lainnya. Kinerja yang baik dari suatu rantai pasok tentunya akan dapat meningkatkan kepuasan konsumen. Oleh karena itu, pengukuran kinerja perlu dilakukan agar suatu rantai pasok dapat mengetahui seberapa baik kinerjanya saat ini dan terus berusaha meningkatkannya. Penelitian ini akan membahas tentang penerapan model supply chain operations reference (SCOR) dan metode perbandingan berpasangan untuk pengukuran kinerja rantai pasok dari sebuah perusahaan yang menghasilkan kemasan produk.
\end{abstract}

Kata kunci: rantai pasok, pengukuran kinerja, SCOR, perbandingan berpasangan

\section{Pendahuluan}

Salah satu aspek fundamental dalam supply chain management (SCM) adalah manajemen kinerja dan perbaikan secara berkelanjutan (Pujawan dan Mahendrawathi, 2010). Menurut Chopra dan Meindl (2007), ada enam faktor penggerak kinerja rantai pasok agar sebuah perusahaan dapat meningkatkan efisiensi dan kecepatan respons, yaitu: 1) facilities, 2) inventory, 3) transportation, 4) information, 5) sourcing, dan 6) pricing.

Untuk menciptakan manajemen kinerja yang efektif diperlukan sistem pengukuran yang mampu mengevaluasi kinerja rantai pasok secara holistik. Sejalan dengan filosofi SCM yang mendorong terjadinya integrasi antar fungsi, pendekatan proses (process-based approach) banyak digunakan untuk merancang sistem pengukuran kinerja rantai pasok (Pujawan dan Mahendrawathi, 2010).

Model acuan berbasis proses yang sering digunakan dalam pengukuran kinerja rantai pasok adalah model supply chain operations reference (SCOR). Model SCOR terkenal karena mampu menghubungkan business processes, performance metrics, standard practices, dan people skills ke dalam sebuah struktur terpadu (APICS, 2018).

Pada model SCOR, proses-proses yang ada di dalam rantai pasok dibagi menjadi lima proses inti, yaitu: 1) plan, 2) source, 3) make, 4) deliver, dan 5) return. Selain itu, terdapat lima 
dimensi umum yang digunakan untuk penentuan atribut metrik atau ukuran kinerja, yaitu: 1) reliability, 2) responsiveness, 3) flexibility, 4) cost, dan 5) assets.

Penelitian yang membahas mengenai struktur model SCOR sudah banyak dilakukan sebelumnya, antara lain: Kasi (2005), Millet dkk. (2009), Zhou dkk. (2011), dan Hwang dkk. (2014). Banyak pula penelitian terdahulu yang terkait dengan penerapan model SCOR di berbagai industri manufaktur, seperti: Yan dkk. (2007) di industri otomotif, Seifbarghy dkk. (2010) di industri penghasil baja, Lestari dkk. (2014) di industri minyak kelapa sawit, dan Sellitto dkk. (2015) di industri sepatu.

Berbagai penelitian sebelumnya juga banyak yang membahas tentang penerapan model SCOR di industri jasa, antara lain: Barnad (2006) di industri health care and insurance, Persson dkk. (2009) di industri construction services, Giannakis (2011) di industri consulting services, dan Weyers (2017) di industri back office services.

Penelitian ini akan membahas mengenai penerapan model SCOR pada pengukuran kinerja rantai pasok dari sebuah perusahaan manufaktur yang menghasilkan kemasan produk (product packaging company). Selain itu, penelitian ini juga akan membahas tentang penerapan dari metode perbandingan berpasangan dalam penentuan bobot setiap atribut metrik kinerja yang digunakan.

\section{Metodologi Penelitian}

Penelitian ini dilakukan dengan mengikuti langkah-langkah sistematis, yaitu:

1. Penelitian pendahuluan,

2. Studi literatur,

3. Perancangan struktur pengukuran kinerja,

4. Pengumpulan data,

5. Pengolahan data dan analisis, serta

6. Penarikan kesimpulan.

\section{Teknik Pengumpulan Data}

Pengumpulan data pada penelitian ini dilakukan dengan teknik penyebaran kuesioner kepada tiga orang responden dari pihak perusahaan untuk memperoleh data matriks perbandingan berpasangan antar kriteria, antar atribut, dan antar sub-kriteria, serta data nilai awal pengukuran kinerja.

\section{Model Penelitian}

Secara garis besar, model dan metode yang digunakan pada penelitian ini, yaitu:

1. Model SCOR

Penggunaan model SCOR pada intinya adalah bertujuan sebagai acuan atau referensi dalam perancangan struktur pengukuran kinerja rantai pasok dari perusahaan yang diteliti, yang terdiri dari kriteria-kriteria (level 1) dan atribut-atribut (level 2). Berdasarkan kriteria dan atribut tersebut, lalu diuraikan lebih lanjut ke dalam berbagai sub-kriteria (level 3).

2. Metode Perbandingan Berpasangan

Untuk menentukan bobot dari setiap atribut metrik kinerja yang telah ditentukan tersebut, maka pada penelitian ini dipakai metode perbandingan berpasangan yang diadaptasi dari Saaty (1993).

Selain itu, pengukuran nilai awal kinerja rantai pasok dilakukan pada tingkat sub-kriteria. Proses normalisasi terhadap skala pengukuran yang berbeda-beda antar sub-kriteria dilakukan dengan menggunakan rumus Snorm De Boer yang diambil dari Trienekens dan Hvolby (2000) sebagai berikut:

$$
\text { Snorm }=\frac{S i-S \min }{S \max -S \min } \times 100 \quad \text { Pers. } 1
$$

dimana:

Smin, Smax, Si : nilai minimum, maksimum, pencapaian aktual dari atribut metrik kinerja.

\section{Hasil dan Pembahasan}

Sebelum pengumpulan data penelitian dilakukan, maka dirancang terlebih dahulu struktur pengukuran kinerja rantai pasok yang akan digunakan pada penelitian ini. Tabel 2. menunjukkan struktur pengukuran kinerja berdasarkan model SCOR dan hasil construct validity ke pihak perusahaan.

Selanjutnya, dilakukan perhitungan bobot untuk seluruh atribut metrik kinerja dari setiap responden, yang bertujuan untuk memeriksa consistency ratio $(\mathrm{CR})$ dari seluruh data matriks perbandingan berpasangan dengan menggunakan rumus berikut:

$$
C R=\frac{C l}{R l}
$$

Pers. 2

dimana:

$R I$ : random index, yang diperoleh dari Saaty (1993) sebagai berikut: 
Tabel 1. Panduan nilai random index

\begin{tabular}{|c|c|c|c|c|c|}
\hline $\boldsymbol{n}$ & 1 & 2 & 3 & 4 & 5 \\
\hline $\boldsymbol{R} \boldsymbol{I}$ & 0,00 & 0,00 & 0,58 & 0,90 & 1,12 \\
\hline $\boldsymbol{n}$ & 6 & 7 & 8 & 9 & 10 \\
\hline $\boldsymbol{R I}$ & 1,24 & 1,32 & 1,41 & 1,45 & 1,51 \\
\hline
\end{tabular}

$\mathrm{Cl}$ : consistency index, yang diperoleh dari rumus sebagai berikut:

$C l=\frac{\lambda \max -n}{n-1}$

Pers. 3

dimana:

Amax : eigen value maksimum

$n$ : jumlah atribut metrik kinerja

Tabel 2. Struktur pengukuran kinerja rantai pasok yang dirancang berdasarkan model SCOR

\begin{tabular}{|c|c|c|c|}
\hline Kriteria (level 1) & Atribut (level 2) & Sub-kriteria (level 3) & Kode \\
\hline \multirow{8}{*}{ Plan (P) } & \multirow{3}{*}{ Reliability (R) } & Pertemuan dengan pemasok & PR-1 \\
\hline & & Pertemuan dengan pelanggan & PR-2 \\
\hline & & Kesesuaian jadwal produksi & PR-3 \\
\hline & \multirow{2}{*}{ Responsiveness (Re) } & Jangka waktu proses penjadwalan produksi & PRe-1 \\
\hline & & Jangka waktu perhitungan biaya produk baru & PRe-2 \\
\hline & Agility (Ag) & Alternatif tak terduga (cth: mesin rusak) & PAg \\
\hline & Cost $(\mathrm{C})$ & Penyimpangan biaya & PC \\
\hline & Assets $(\mathrm{A})$ & Cash-to-cash cycle time & PA \\
\hline \multirow{8}{*}{ Source (S) } & \multirow{4}{*}{ Reliability (R) } & Kualitas bahan baku & SR-1 \\
\hline & & Ketepatan waktu pemenuhan bahan baku & SR-2 \\
\hline & & Ketepatan jumlah bahan baku & SR-3 \\
\hline & & Service level yang dapat diberikan & SR-4 \\
\hline & \multirow{2}{*}{ Responsiveness (Re) } & Jangka waktu pemenuhan bahan baku & SRe-1 \\
\hline & & Respons terhadap keluhan & SRe-2 \\
\hline & Agility (Ag) & Ketersediaan pemasok & SAg \\
\hline & Cost (C) & Daya saing harga & SC \\
\hline \multirow{5}{*}{ Make (M) } & \multirow{3}{*}{ Reliability (R) } & Kesesuaian dengan spesifikasi produk & MR-1 \\
\hline & & Ketepatan pengepakan (packing) & MR-2 \\
\hline & & Jumlah produk cacat & MR-3 \\
\hline & Agility (Ag) & Fleksibilitas dalam pembuatan produk & MAg \\
\hline & Cost (C) & Kesesuaian biaya & $\mathrm{MC}$ \\
\hline \multirow{4}{*}{ Deliver (D) } & \multirow{4}{*}{ Reliability (R) } & Tingkat pemenuhan pesanan setiap pengiriman & DR-1 \\
\hline & & Ketepatan jumlah produk yang dikirim & DR-2 \\
\hline & & Ketepatan jenis produk yang dikirim & DR-3 \\
\hline & & Kualitas produk setelah proses pengiriman & DR-4 \\
\hline \multirow{4}{*}{ Return (R) } & \multirow{2}{*}{ Reliability (R) } & Tingkat keluhan pelanggan & RR-1 \\
\hline & & Reject rate dari pelanggan & RR-2 \\
\hline & \multirow{2}{*}{ Responsiveness $(\mathrm{Re})$} & Jangka waktu menanggapi keluhan & $\mathrm{RRe}-1$ \\
\hline & & Jangka waktu penggantian produk reject & $\mathrm{RRe}-2$ \\
\hline
\end{tabular}

Perhitungan bobot dari setiap atribut metrik kinerja juga dilakukan secara multi-partisipan untuk memperoleh bobot gabungan dari seluruh responden, dimana data matriks perbandingan berpasangan gabungan dapat diperoleh dengan rumus sebagai berikut:

$$
X g a b=\left(X_{1} \times X_{2} \times \ldots \times X_{n}\right)^{1 / n} \quad \text { Pers. } 4
$$

dimana:

$X g a b$ : nilai gabungan seluruh responden

$X_{i}$ : nilai responden ke- $i$

$n$ : jumlah responden

Untuk memeriksa konsistensi dari kriteria, atribut, dan sub-kriteria yang digunakan dalam pengukuran kinerja rantai pasok pada penelitian ini, maka dilakukan perhitungan consistency ratio hierarchy $(\mathrm{CRH})$ dengan rumus sebagai berikut:

$$
C R H=\frac{\text { Total } C I H}{\text { Total } R I H}
$$

Pers. 5

dimana:

$\mathrm{CIH}$ : consistency index hierarchy

$R I H$ : random index hierarchy

Pada penelitian ini, seluruh data matriks perbandingan berpasangan yang digunakan dapat dinyatakan konsisten karena seluruh nilai $\mathrm{CR}$ yang diperoleh memenuhi standar menurut Saaty (1993) sebagai berikut:

Tabel 3. Standar nilai consistency ratio

\begin{tabular}{|c|c|c|c|c|}
\hline Matrix & $2 \times 2$ & $3 \times 3$ & $4 \times 4$ & $\geq 5 \times 5$ \\
\hline $\boldsymbol{C R}$ & $0 \%$ & $\leq 5 \%$ & $\leq 8 \%$ & $\leq 10 \%$ \\
\hline
\end{tabular}


Selain itu, seluruh kriteria, atribut, dan subkriteria yang digunakan juga dapat dinyatakan konsisten secara hierarki karena pada penelitian ini diperoleh nilai $\mathrm{CRH}$ yang lebih kecil dari $10 \%$, yaitu sebesar $2,14 \%$.

Selanjutnya, dilakukan perhitungan bobot global untuk mengetahui urutan atau prioritas kepentingan dari kriteria, atribut, dan sub- kriteria yang diukur pada penelitian ini dengan rumus sebagai berikut:

Bobot global $=$ bobot kriteria $\times$ bobot atribut $x$ bobot sub-kriteria

Pers. 6

Nilai akhir kinerja rantai pasok dihitung dengan mengalikan nilai awal kinerja dari hasil rumus Snorm De Boer dengan bobot global, dan hasilnya ditunjukkan pada Tabel 4.

Tabel 4. Nilai akhir kinerja rantai pasok dengan metode perbandingan berpasangan dan Snorm De Boer

\begin{tabular}{|c|c|c|c|c|c|c|c|c|}
\hline Kriteria & Bobot & Atribut & Bobot & $\begin{array}{c}\text { Sub- } \\
\text { kriteria }\end{array}$ & Bobot & $\begin{array}{l}\text { Bobot } \\
\text { global }\end{array}$ & $\begin{array}{l}\text { Nilai } \\
\text { awal }\end{array}$ & $\begin{array}{l}\text { Nilai } \\
\text { akhir }\end{array}$ \\
\hline \multirow{8}{*}{ Plan } & \multirow{8}{*}{0,062} & \multirow{3}{*}{ Reliability } & \multirow{3}{*}{0,296} & PR-1 & 0,240 & 0,0044 & 70 & 0,3071 \\
\hline & & & & PR-2 & 0,167 & 0,0030 & 80 & 0,2433 \\
\hline & & & & PR-3 & 0,593 & 0,0108 & 40 & 0,4328 \\
\hline & & \multirow{2}{*}{ Responsiveness } & \multirow{2}{*}{0,145} & PRe-1 & 0,325 & 0,0029 & 70 & 0,2038 \\
\hline & & & & PRe-2 & 0,675 & 0,0061 & 80 & 0,4846 \\
\hline & & Agility & 0,070 & PAg & 1,000 & 0,0043 & 100 & 0,4326 \\
\hline & & Cost & 0,448 & PC & 1,000 & 0,0277 & 90 & 2,4904 \\
\hline & & Assets & 0,041 & PA & 1,000 & 0,0025 & 80 & 0,2036 \\
\hline \multirow{8}{*}{ Source } & \multirow{8}{*}{0,111} & \multirow{4}{*}{ Reliability } & \multirow{4}{*}{0,429} & SR-1 & 0,403 & 0,0193 & 80 & 1,5419 \\
\hline & & & & SR-2 & 0,379 & 0,0181 & 70 & 1,2658 \\
\hline & & & & SR-3 & 0,091 & 0,0043 & 60 & 0,2608 \\
\hline & & & & SR-4 & 0,127 & 0,0061 & 80 & 0,4859 \\
\hline & & \multirow{2}{*}{ Responsiveness } & \multirow{2}{*}{0,150} & SRe-1 & 0,712 & 0,0119 & 70 & 0,8356 \\
\hline & & & & SRe-2 & 0,288 & 0,0048 & 40 & 0,1936 \\
\hline & & Agility & 0,063 & SAg & 1,000 & 0,0071 & 100 & 0,7061 \\
\hline & & Cost & 0,358 & SC & 1,000 & 0,0399 & 80 & 3,1905 \\
\hline \multirow{5}{*}{ Make } & \multirow{5}{*}{0,499} & \multirow{3}{*}{ Reliability } & \multirow{3}{*}{0,568} & MR-1 & 0,737 & 0,2088 & 70 & 14,6181 \\
\hline & & & & MR-2 & 0,094 & 0,0268 & 100 & 2,6786 \\
\hline & & & & MR-3 & 0,169 & 0,0479 & 70 & 3,3541 \\
\hline & & Agility & 0,119 & MAg & 1,000 & 0,0594 & 80 & 4,7553 \\
\hline & & Cost & 0,313 & $\mathrm{MC}$ & 1,000 & 0,1560 & 70 & 10,9196 \\
\hline \multirow{4}{*}{ Deliver } & \multirow{4}{*}{0,285} & \multirow{4}{*}{ Reliability } & \multirow{4}{*}{1,000} & DR-1 & 0,081 & 0,0231 & 80 & 1,8468 \\
\hline & & & & DR-2 & 0,120 & 0,0340 & 80 & 2,7223 \\
\hline & & & & DR-3 & 0,265 & 0,0756 & 100 & 7,5558 \\
\hline & & & & DR-4 & 0,534 & 0,1519 & 80 & 12,1550 \\
\hline \multirow{4}{*}{ Return } & \multirow{4}{*}{0,043} & \multirow{2}{*}{ Reliability } & \multirow{2}{*}{0,781} & RR-1 & 0,325 & 0,0109 & 80 & 0,8751 \\
\hline & & & & RR-2 & 0,675 & 0,0228 & 70 & 1,5927 \\
\hline & & \multirow{2}{*}{ Responsiveness } & \multirow{2}{*}{0,219} & RRe-1 & 0,325 & 0,0031 & 100 & 0,3075 \\
\hline & & & & RRe-2 & 0,675 & 0,0064 & 90 & 0,5757 \\
\hline & & & & & & Total $\mathbf{n}$ & akhir & 77,2354 \\
\hline
\end{tabular}

Berdasarkan hasil perhitungan bobot kriteria, dapat diketahui bahwa prioritas kepentingan dari kriteria (level 1) bagi pihak perusahaan berturut-turut adalah kriteria make, deliver, source, plan, dan return. Untuk lebih jelasnya, perbandingan bobot dari setiap kriteria dapat dilihat pada Gambar 1.

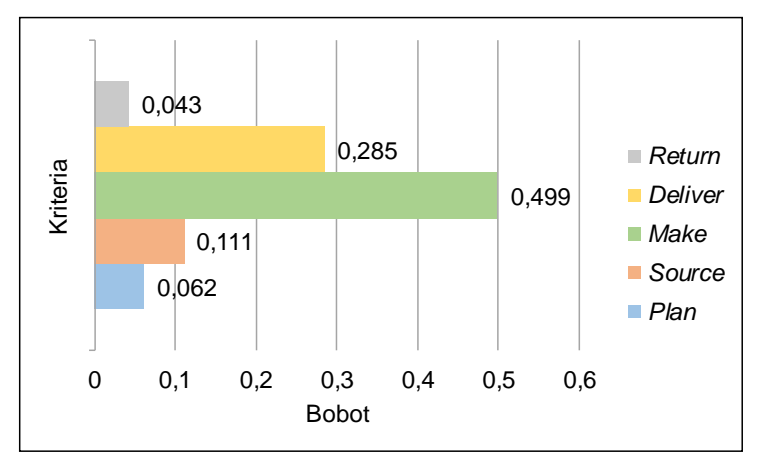

Gambar 1. Perbandingan bobot kriteria 
Dari segi atribut (level 2), maka atribut yang terpenting bagi pihak perusahaan pada kriteria plan adalah atribut cost dengan bobot sebesar 0,448; sedangkan pada kriteria source, make, deliver, dan return adalah atribut reliability dengan bobot masing-masing sebesar 0,429; 0,568; 1,000; dan 0,781; selengkapnya dapat dilihat pada Gambar 2. hingga Gambar 6.

Kemudian, dari segi sub-kriteria (level 3), maka tiga sub-kriteria yang paling utama bagi pihak perusahaan adalah sub-kriteria MR-1, MC, dan DR-4 dengan bobot global sebesar 0,2088; 0,1560; dan 0,1519; untuk lebih lengkapnya dapat dilihat pada Gambar 7.

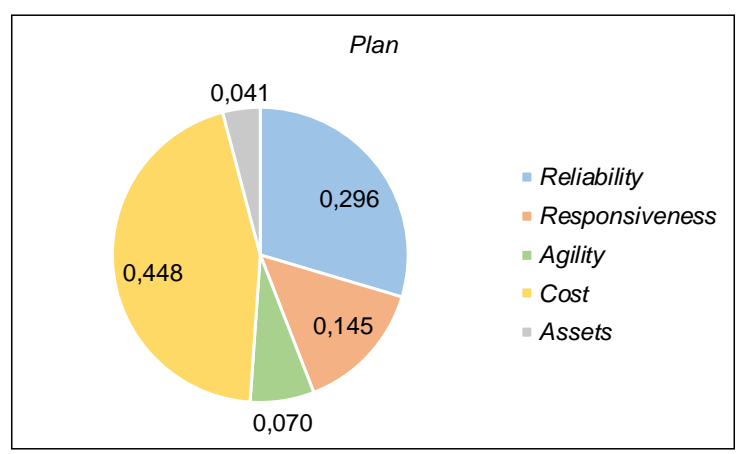

Gambar 2. Proporsi bobot atribut kriteria plan

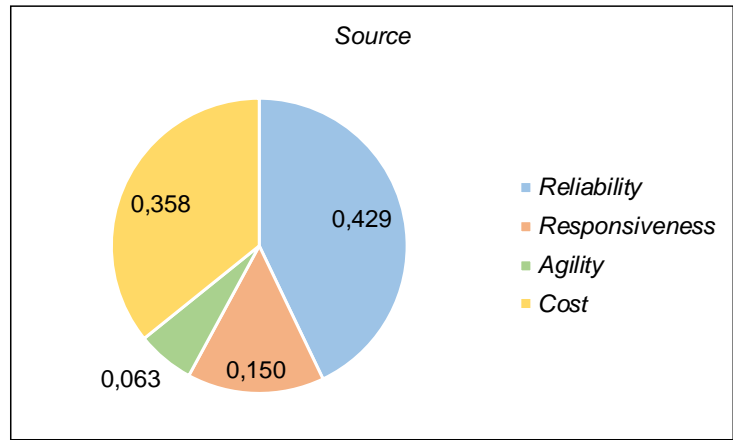

Gambar 3. Proporsi bobot atribut kriteria source

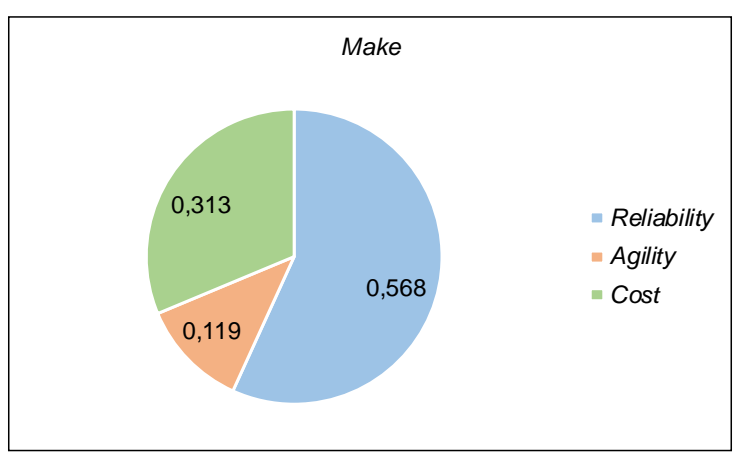

Gambar 4. Proporsi bobot atribut kriteria make

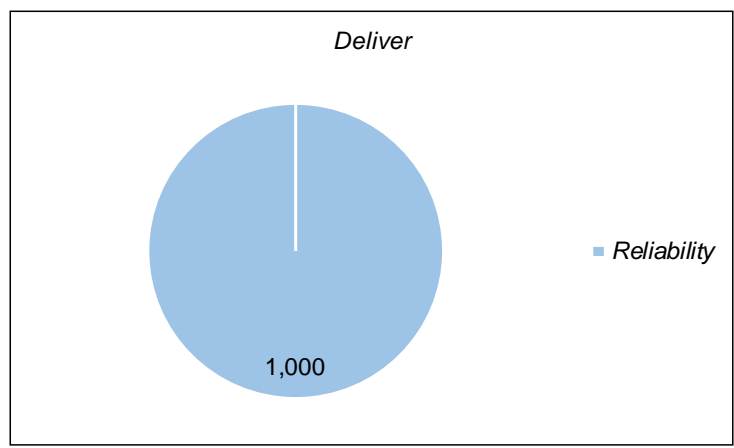

Gambar 5. Proporsi bobot atribut kriteria deliver

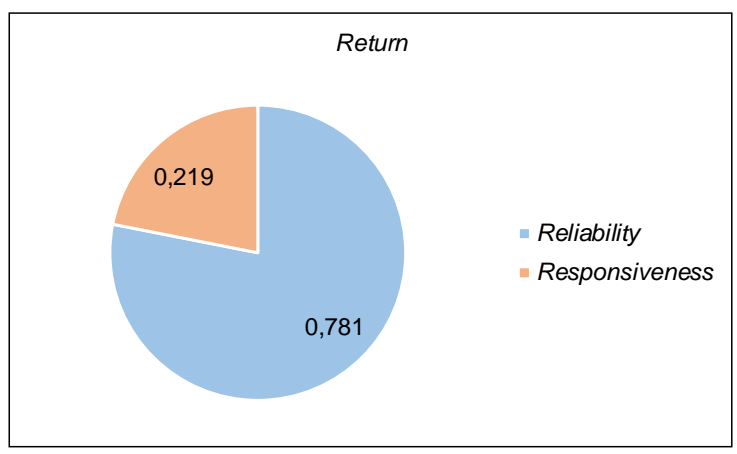

Gambar 6. Proporsi bobot atribut kriteria return

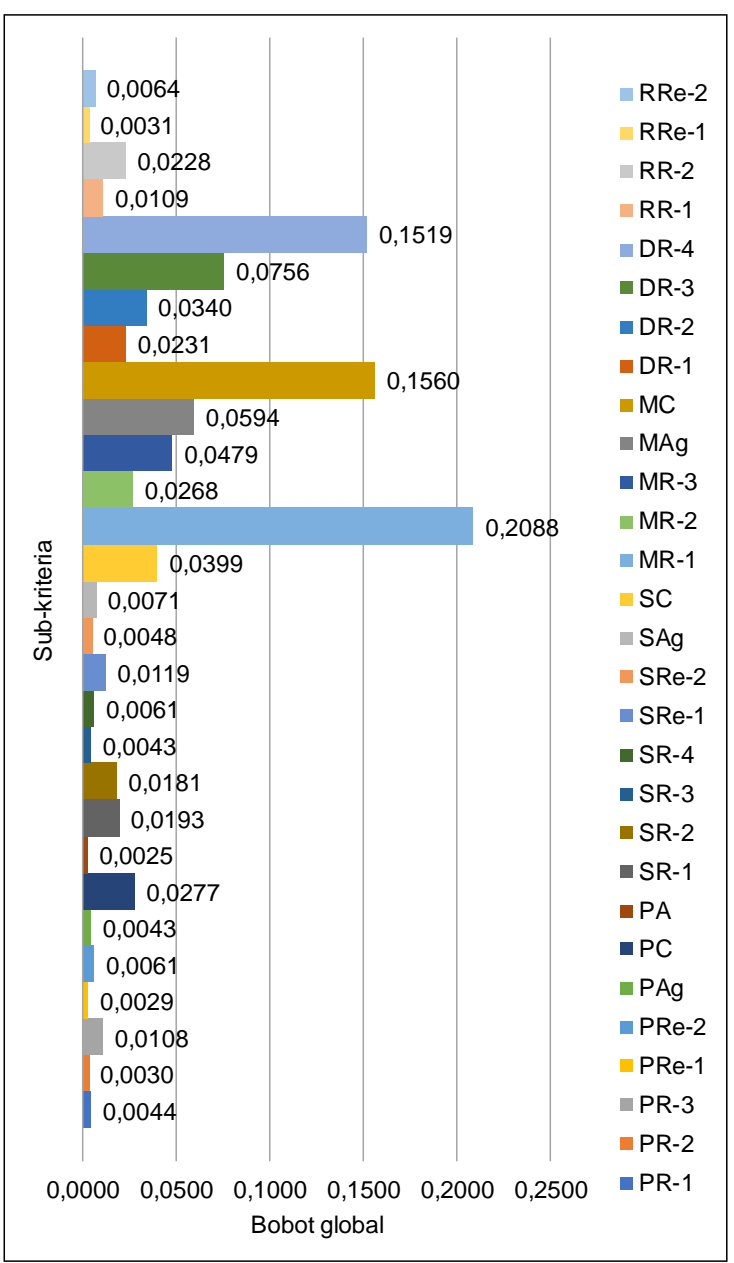

Gambar 7. Perbandingan bobot global 
Pengukuran kinerja rantai pasok dari perusahaan yang diteliti menghasilkan total nilai akhir sebesar 77,2354. Jika mengacu pada standar dari Trienekens dan Hvolby (2000) pada Tabel 5., maka hal ini menunjukkan bahwa kinerja saat ini dari rantai pasok perusahaan tersebut sudah baik.

Tabel 5. Standar nilai kinerja rantai pasok

\begin{tabular}{|c|c|}
\hline Monitoring system & Performance indicator \\
\hline$<40$ & Poor \\
\hline $40-50$ & Marginal \\
\hline $50-70$ & Average \\
\hline $70-90$ & Good \\
\hline$>90$ & Excellent \\
\hline
\end{tabular}

\section{Kesimpulan}

Penelitian ini menggabungkan penerapan model SCOR dan metode perbandingan berpasangan (pairwise comparison) dalam melakukan pengukuran kinerja rantai pasok dari sebuah perusahaan pembuat kemasan produk. Dari hasil yang diperoleh, dapat diketahui bahwa atribut metrik kinerja yang memiliki prioritas kepentingan tertinggi adalah kriteria make $(\mathrm{M})$, atribut reliability $(\mathrm{R})$, dan subkriteria MR-1 (kesesuaian dengan spesifikasi produk).

Secara keseluruhan, kinerja saat ini dari rantai pasok perusahaan tersebut sudah baik (good). Untuk selanjutnya, penelitian ini masih dapat dikembangkan ke arah perumusan strategi-strategi untuk peningkatan kinerja rantai pasok dari perusahaan tersebut menjadi lebih baik lagi (from good to excellent).

\section{Daftar Pustaka}

APICS, Supply Chain Operations Reference (SCOR) Framework, [Online], Diakses dari http://www.apics.org/apics-for-business/ frameworks/scor/ [2018, 30 September].

Barnad, J. H. (2006). A Multi-view Framework for Defining the Services Supply Chain Using Object Oriented Methodology. Ph.D. Thesis, University of Central Florida, USA.

Chopra, S. \& Meindl, P. (2007). Supply Chain Management: Strategy, Planning, \& Operations (3rd ed.). New Jersey: Pearson Prentice Hall.

Giannakis, M. (2011). Management of Service Supply Chains with A Service-oriented Reference Model: The Case of Management Consulting. Supply Chain Management: An International Journal, Vol. 16(5), 346-361.
Hwang, G., Han, S., Jun, S., \& Park, J. (2014). Operational Performance Metrics in Manufacturing Process: Based on SCOR Model and RFID Technology. International Journal of Innovation, Management, and Technology, Vol. 5(1), 50-55.

Kasi, V. (2005). Systemic Assessment of SCOR for Modeling Supply Chains. Proceedings of the 38th Hawaii International Conference of System Sciences, Big Island, Hawaii, 1-10.

Lestari, F., Ismail K., Hamid A. A., Supriyanto, E., Yanti, N., \& Sutopo, W. (2014). Supply Chain Configuration Using Hybrid SCOR Model and Discrete Event Simulation. Proceedings of the World Congress on Engineering, London, UK, 967-972.

Millet, P. A., Phillip, S., \& Valerie, B. G. (2009). The SCOR Model for the Allignment of Business Processes and Information Systems. Enterprise Information Systems, Vol. 3(4), 393-407.

Persson, F., Bengtsson, J., \& Gustad, O. (2009). Construction Logistics Improvement Using the SCOR Model - Tornet Case. Proceedings of International Conference on Advances in Production Management Systems, Bordeaux, France, 211-218.

Pujawan, I. N. \& Mahendrawathi, E. R. (2010). Supply Chain Management (2nd ed.). Surabaya: Guna Widya.

Saaty, T. L. (1993). Decision Making for Leader: The Analytical Hierarchy Process for Decision in Complex World. Pittsburgh: Prentice Hall.

Seifbarghy, M., Akbari, M. R., \& Sajadieh, M. S. (2010). Analyzing the Supply Chain Using SCOR Model in A Steel Producing Company. Proceedings of the 40th International Conference on Computers \& Industrial Engineering, Awaji Island, Japan, 1-6.

Sellitto, M. A., Pereira, G. M., Borchardt, M., Da Silva, R. I., \& Viegas, C. V. (2015). A SCORbased Model for Supply Chain Performance Measurement: Application in the Footwear Industry. International Journal of Production Research, Vol. 53(16), 4917-4926.

Trienekens, J. H. \& Hvolby, H. H. (2000). Performance Measurement and Improvement in Supply Chains. Proceedings of the 3rd CINet Conference: Cl2000 From Improvement to Innovation, 399-408.

Weyers, M. (2017). An Application of the Supply Chain Operations Reference Model for the 
Service Supply Chain for Standardised Back Office Services. Ph.D. Thesis, Stellenbosch University, South Africa.

Yan, J., Li, K., \& Qiu, D. (2007). A SCOR-based Method for Supply Chain Process Reengineering with Applications in Chinese Automotive Industry. Proceedings of the 13th Americas Conference on Information Systems, 226.

Zhou, H., Benton Jr., W. C., Schilling, D. A., \& Milligan, G. W. (2011). Supply Chain Integration and the SCOR Model. Journal of Business Logistics, Vol. 32(4), 332-344. 